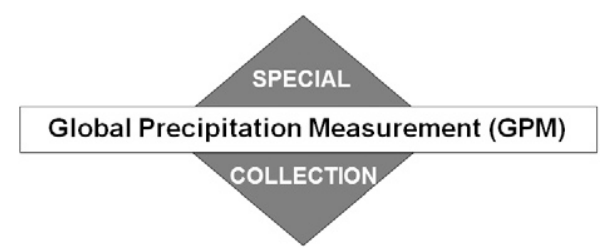

\title{
A Field Study of Footprint-Scale Variability of Raindrop Size Distribution
}

\author{
Ali TOKAY \\ Joint Center for Earth Systems Technology, University of Maryland, Baltimore County, and NASA Goddard Space \\ Flight Center, Greenbelt, Maryland \\ LEO PIO D'ADDERIO \\ Department of Physics and Earth Science, University of Ferrara, Ferrara, Italy \\ FEDERICO PORCÙ \\ Department of Physics and Astronomy, University of Bologna, Bologna, Italy \\ DAVID B. WOLFF \\ Wallops Flight Facility, NASA Goddard Space Flight Center, Wallops Island, Virginia \\ WALter A. Petersen \\ NASA Marshall Space Flight Center, Huntsville, Alabama
}

(Manuscript received 6 January 2017, in final form 24 August 2017)

\begin{abstract}
A network of seven two-dimensional video disdrometers (2DVD), which were operated during the Midlatitude Continental Convective Clouds Experiment (MC3E) in northern Oklahoma, are employed to investigate the spatial variability of raindrop size distribution (DSD) within the footprint of the dual-frequency precipitation radar (DPR) on board the National Aeronautics and Space Administration's Global Precipitation Measurement (GPM) mission core satellite. One-minute 2DVD DSD observations were interpolated uniformly to 13 points distributed within a nearly circular DPR footprint through an inverse distance weighting method. The presence of deep continental showers was a unique feature of the dataset resulting in a higher mean rain rate $R$ with respect to previous studies. As a measure of spatial variability for the interpolated data, a three-parameter exponential function was applied to paired correlations of three parameters of normalized gamma DSD, $R$, reflectivity, and attenuation at Ka- and Ku-band frequencies of DPR (Z_Ka, Z_Ku, k_Ka, and k_Ku, respectively). The symmetry of the interpolated sites allowed quantifying the directional differences in correlations at the same distance. The correlation distances $d_{0}$ of $R, \mathrm{k} \_\mathrm{Ka}$, and $\mathrm{k} \_\mathrm{Ku}$ were approximately $10 \mathrm{~km}$ and were not sensitive to the choice of four rain thresholds used in this study. The $d_{0}$ of $Z \_K u$, on the other hand, ranged from 29 to $20 \mathrm{~km}$ between different rain thresholds. The coefficient of variation $(\mathrm{CV})$ remained less than 0.5 for most of the samples for a given physical parameter, but a CV of greater than 1.0 was also observed in noticeable samples, especially for the shape parameter and $\mathrm{Z} \_\mathrm{Ku}$.
\end{abstract}

\section{Introduction}

The retrieval of raindrop size distribution (DSD) from the dual frequency precipitation radar (DPR) on board the National Aeronautics and Space Administration (NASA) Global Precipitation Measurement (GPM) core satellite is one of the key objectives of the GPM

Corresponding author: Ali Tokay, tokay@umbc.edu mission. The footprint of the DPR is nearly circular with an approximately $5-\mathrm{km}$ diameter. Variability of the DSD within the footprint represents one significant form of nonuniform beam filling (NUBF) and is manifested as an uncertainty in the retrieved size distribution. The NUBF occurs in both the horizontal and vertical dimensions and results from the combination of the gradient of rain intensity and partial filling of precipitation within the footprint. Embedded convection 
and squall lines with trailing stratiform rain are frequently observed during frontal passages and result in sharp gradients in rain intensity within a few kilometers. Air mass thunderstorms and patchy stratiform rain in the presence of the dry layer near Earth's surface result in gaps in the DPR footprint.

The vast majority of the previous NUBF studies have focused on the horizontal spatial variability of rainfall using networks of rain gauges. Among those, Ciach and Krajewski (2006) conducted a well-designed experimental study, which allowed examination of the spatial variability at various time scales for different events. The long-term observations as well as the continuity in the record are the key factors in studying the spatial variability of different weather systems. Tokay and Öztürk (2012) and Tokay et al. (2014) conducted 2- and 5-yr-long gauge-based spatial variability studies in the mid-Atlantic region, respectively, and found substantial differences in correlation distances between frontal systems, summer convection, tropical cyclones, and nor'easters.

The gauge-based spatial variability studies mentioned above and a number of other studies (e.g., Habib and Krajewski 2002; Gebremichael and Krajewski 2004) used tipping-bucket gauges with a tip resolution of $0.254 \mathrm{~mm}$. To avoid random sampling and quantization errors, these studies considered $5 \mathrm{~min}$ or longer periods of integration. From the GPM mission point of view, the interest is instantaneous NUBF and goes beyond rain intensity to include measured reflectivities at the $\mathrm{Ka}-\left(\mathrm{Z} \_\mathrm{Ka}\right)$ and $\mathrm{Ku}$-bands $\left(\mathrm{Z} \_\mathrm{Ku}\right)$ and derived DSD parameters. Disdrometers, which provide reliable DSD measurements at 1-min resolution, are adequate to quantify the DSD and integral rain parameters at the site. Early disdrometerbased spatial variability studies employed only three (Tokay and Bashor 2010) or four (Lee et al. 2009; Schröer 2011) units, and their findings were limited to quantifying the spatial variability within a single satellite footprint.

With the availability of cost effective laser-optical disdrometers (Parsivel and Thies) there has been a noticeable increase in the number of disdrometer-based spatial variability studies. Tapiador et al. (2010) demonstrated differences in coefficient and exponents of the reflectivity versus rain rate relationships that were derived from eight pairs of Parsivel disdrometers (LöfflerMang and Joss 2000) individually, where the maximum separation distance was nearly $3 \mathrm{~km}$. As a follow-up study, Tapiador et al. (2017) concluded that a single instrument underestimates the instantaneous rain rate as high as $70 \%$. Jaffrain and Berne (2012), on the other hand, quantified spatial variability of three DSD-derived parameters employing 16 Parsivel disdrometers in a $1 \mathrm{~km} \times 1 \mathrm{~km}$ array. Rather than studying the spatial variability of moments of DSD, Jameson et al. (2015) investigated the variability of DSD at each size bin using 21 Thies laser-optical disdrometers (Frasson et al. 2011) in a $100 \mathrm{~m} \times 100 \mathrm{~m}$ array. They determined that the spatial variability increased with increasing the size of the network and with increasing drop size. In a different study of rain microstructure, Jameson et al. (2016) showed significant differences in total concentration and rain rate across the $10 \mathrm{~cm} \times 10 \mathrm{~cm}$ grid of the twodimensional video disdrometer (2DVD).

The abovementioned gauge- and disdrometer-based studies demonstrate that the spatial variability of DSDs exists from submeter to kilometer scales. For this study, the main interest is the spatial variability of DSDs and selected rain parameters within the DPR footprint. The outcome of field-based spatial variability depends on a number of factors, including the configuration of surfacebased instruments, precipitation regime, and period of observations. For a disdrometer network, the dependency on choice of instrument and representation of point measurements for calculating the areal mean are common issues. Tokay et al. (2016) showed a good agreement in correlation distance of most DSD and rain parameters between 2DVD and OTT Parsivel ${ }^{2}$. Their study was conducted in the mid-Atlantic region of the United States in predominantly stratiform rain. Raupach and Berne (2016a), on the other hand, gridded DSDs at $100 \mathrm{~m} \times 100 \mathrm{~m}$ resolution over a $6 \mathrm{~km} \times 9 \mathrm{~km}$ area using a Parsivel network in southeastern France. This pioneer study used ordinary kriging, taking into account the nonstationary aspect of rainfall due to intermittency. The X-band observed and DSD-derived horizontal reflectivity fields were in a good agreement, even though there were noticeable differences in reflectivity intensities. Raupach and Berne (2016b) used the same dataset and methodology to investigate the errors due to the representation of point measurements for areal DSD estimates. This study focused on singleand dual-frequency DSD parameters retrieved from simulated GPM DPR measurements. They pointed out that the rain rate and reflectivity fields were reproduced from GPM-style retrieval methods.

Fast scanning ground-based radars are an invaluable asset for determining the NUBF of the satellite footprint. Moreau et al. (2009) utilized X-band, dualpolarized radar rainfall estimates at $1 \mathrm{~km} \times 1 \mathrm{~km}$ resolution and determined that the spatial correlations were in a very good agreement with those from the gauge network underneath. Thurai et al. (2012) examined the spatial variability of two DSD parameters and rain rate from a C-band dual-polarization radar beam overhead of two collocated 2DVDs in northern Alabama. Two 2DVDs were used as a reference for the accuracy of radar-derived DSD parameters but were not sufficient 
to be used to verify the spatial variability. Bringi et al. (2015), on the other hand, investigated the spatial variability of the same three parameters from an S-band dual-polarization radar and 2DVD network underneath for one convective and one stratiform event during the Midlatitude Continental Convective Experiment (MC3E; Jensen et al. 2016). The stratiform event was long enough to have reliable correlations between the six 2DVDs, and a reasonable agreement was evident between the radar- and 2DVD-derived rain rate and normalized intercept parameter of the gamma distribution, but not for median volume diameter.

Precipitation products such as the National Oceanic and Atmospheric Administration/National Severe Storms Laboratory (NOAA/NSSL) Next-Generation National Mosaic and Multi-Sensor Quantitative Precipitation Estimation system (NMQ Q2) are another resource to quantify the NUBF. Since this is a national product, the quantitative comparison between ground and satellite products can be done statistically. Kirstetter et al. (2015) compared NMQ Q2 with NASA's Tropical Rainfall Measurement Mission Precipitation Radar, which had approximately the same footprint size of the GPM DPR. They found out that NUBF increases as the convective fraction increases and as percent coverage and rain intensity decrease. They also pointed out that the conversion between radar reflectivity and rain rate, nonprecipitating echoes, and time and height ambiguity are sources of errors.

This study investigates the horizontal spatial variability of DSDs, which is mainly due to the gradients of rain intensity within the DPR footprint. It does not consider the migration of the storm within the footprint. It is a field-campaign-based study, as introduced in section 2. Section 3 describes the three-parameter exponential function, which is employed to quantify the spatial variability. The DSD and selected integral rain parameters are laid out in sections 4 and 5, respectively. Section 6 describes the inverse distance weighting (IDW), which is employed to interpolate the DSD at sites of interest. The probability density functions (PDFs) of eight physical parameters are presented in section 7. Section 8 is dedicated to the spatial variability, which is composed of the dependency of the correlation coefficient to the distance and the coefficient of variation (CV) within the DPR footprint. The relevance of this study to the GPM mission is outlined in section 9, followed by conclusions in section 10 .

\section{Field campaign}

The MC3E campaign was a joint effort involving the U.S. Department of Energy's Atmospheric Radiation
Measurement (ARM) and the NASA GPM ground validation (GPMGV) programs. The campaign was conducted in north-central Oklahoma $\left(36.7^{\circ} \mathrm{N}, 97.1^{\circ} \mathrm{W}\right)$ from 22 April through 6 June 2011 (Jensen et al. 2016). Seven (five GPMGV and two ARM) third-generation compact 2DVDs (Schönhuber et al. 2007) were deployed at and around the ARM Southern Great Plains site, where the distances ranged from 0.4 to $9.2 \mathrm{~km}$ (Table 1). Given the fact that the 2DVDs require power and open space, the logistics dominate the site selection. For the purpose of this study, it would have been desirable to have uniformly distributed units within a circular area with a diameter of $5 \mathrm{~km}$ representing the DPR footprint. This was not feasible because of the power and open space requirements of site selection. However, the layout and number of units allowed interpolating the 2DVD measurements to desired sites. Figure 1 shows the locations and interpolation points of the 2DVDs (hereafter, the interpolation points will be treated as pseudo sites). The locations are given based on serial number (SN), while the interpolated sites are numbered from 1 to 13. Table 2 presents the coordinates and distances between the interpolated sites. Because of symmetry, the distances between the interpolated sites can be the same. For instance, site 1 is a distance of $2.5 \mathrm{~km}$ from sites 2, 3, 4, and 5. This configuration allowed studying the directional changes in the correlations based on storm orientation.

The 2DVDs are delicate instruments and are not ideal for continuous unattended operation under extreme weather conditions. Indeed, the strong winds and heavy rain resulted in several 2DVD operation failures during the experiment. To mitigate the data dropouts, this study focused on the dataset only when all units reported rainfall. The standard processing by the GPMGV defines the rainy minutes as having a minimum rain rate of $0.01 \mathrm{~mm} \mathrm{~h}^{-1}$ and a minimum number of 10 drops sampled in 1-min observations. This resulted in an MC3E database of 740 one-minute samples, which were the input for the interpolation routine.

The rain/no-rain threshold determines the sample size, which is linked to definition of a rain event (Larsen and Teves 2015). As noted in previous studies (e.g., Raupach and Berne 2016a,b; Kirstetter et al. 2015), the rain intermittence is frequently observed in light stratiform rain and plays an important role in NUBF. We addressed this matter by setting DSD-derived rain rates less than $0.1 \mathrm{~mm} \mathrm{~h}^{-1}$ as zero after interpolation. This eliminated five samples where the rain rate fell below the threshold at all 13 sites. Surprisingly, only 34 samples had zero rainfall at one or more sites for the remaining dataset. Since the DPR footprint is a single data point from the GPM perspective, the areal average rainfall is 
TABLE 1. Coordinates of the seven 2DVD units with their serial numbers during MC3E. The distances between the seven sites are given in kilometers.

\begin{tabular}{|c|c|c|c|c|c|c|c|}
\hline & SN25 & SN35 & SN36 & SN37 & SN38 & SN46 & SN47 \\
\hline & $36.623^{\circ} \mathrm{N}$ & $36.618^{\circ} \mathrm{N}$ & $36.581^{\circ} \mathrm{N}$ & $36.632^{\circ} \mathrm{N}$ & $36.578^{\circ} \mathrm{N}$ & $36.606^{\circ} \mathrm{N}$ & $36.604^{\circ} \mathrm{N}$ \\
\hline & $97.532^{\circ} \mathrm{W}$ & $97.479^{\circ} \mathrm{W}$ & $97.479^{\circ} \mathrm{W}$ & $97.481^{\circ} \mathrm{W}$ & $97.445^{\circ} \mathrm{W}$ & $97.488^{\circ} \mathrm{W}$ & $97.485^{\circ} \mathrm{W}$ \\
\hline SN25 & & 4.75 & 6.67 & 4.65 & 9.24 & 4.37 & 4.70 \\
\hline SN35 & & & 4.14 & 1.58 & 5.40 & 1.53 & 1.65 \\
\hline SN36 & & & & 5.72 & 3.03 & 2.93 & 2.63 \\
\hline SN37 & & & & & 6.84 & 2.95 & 3.16 \\
\hline SN38 & & & & & & 4.94 & 4.59 \\
\hline SN46 & & & & & & & 0.36 \\
\hline
\end{tabular}

considered to determine the rainy footprint. Hence, a rain rate threshold of $0.1 \mathrm{~mm} \mathrm{~h}^{-1}$ was applied to the areal average rainfall and 12 more samples were eliminated, leaving 723 samples. At least 4 out of 13 sites had zero rainfall in these 12 samples, even though one sample had 5 zero-rainfall sites, but areal average rainfall was above the threshold.

Since the goal of this study is to determine the spatial variability of rain within the DPR footprint, the reflectivity thresholds at $\mathrm{Ku}$ and $\mathrm{Ka}$ bands have also been considered. Prior to GPM launch, Seto et al. (2013) reported the minimum detectable signals (MDSs) for the DPR of $18 \mathrm{~dB} Z$ at Ku band and $12 \mathrm{~dB} Z$ for the Ka-band footprints, and these thresholds were adopted in Tokay et al. (2016) and Raupach and Berne (2016b). PostGPM launch, the MDSs are currently $13 \mathrm{dBZ}$ for the high-sensitivity Ka-band swath (HS) and Ku-band normal swath (NS). The MDS for the matched Ka- and Ku-band swath (MS) is $18 \mathrm{dBZ}$ (R. Meneghini 2016, personal communication). The corresponding sample sizes were 703 and 698 for HS and NS, respectively, and 639 for MS (Table 3). The areal average Z_Ka and $\mathrm{Z} \_\mathrm{Ku}$ were considered in determining the MDS. While these sample sizes are adequate to determine the correlations, it was not feasible to examine the spatial variability on an event basis or precipitation type.

\section{Methodology}

A three-parameter exponential function has widely been used in gauge (Ciach and Krajewski 2006), disdrometer (Tokay et al. 2016), and radar-based (Bringi et al. 2015) spatial variability studies and is adopted to investigate the spatial variability of DSD and integral rain parameters. The exponential function is expressed as

$$
r=r_{0} \exp \left[-\left(\frac{d}{d_{0}}\right)^{s_{0}}\right],
$$

where $r_{0}$ and $s_{0}$ are nugget and shape parameters, respectively, and $d_{0}$ is the correlation distance. The
Pearson correlation coefficient $r$ is calculated between the paired 2DVD observations at distance $d$. The $r_{0}$ is the nugget correlation between the collocated observations and is set to 0.99 in the absence of collocated 2DVDs. It should be noted that there is variability in drop counts at spatial scales of 1-100 m (Jameson and Larsen 2016; Jameson et al. 2016), but the correlations of derived DSD and integral rain parameters are mainly higher than 0.90 as shown in Tokay and Öztürk (2012) for rainfall.

Following Tokay et al.'s (2016) methodology, an initial guess was made for $d_{0}$ and $s_{0}$ using ranges of $0-300$ and $0-2$ at increments of 0.1 and 0.01 , respectively. The $d_{0}$ and $s_{0}$ are calculated minimizing the root-meansquare error (RMSE) between the observation and equation-based correlations. The RMSE is the measure of the goodness of the fit and is critical for the interpretation of $d_{0}$ and $s_{0}$.

Figure 2 shows the sensitivity of $d_{0}$ to $r$ for six different $s_{0}$ when $d$ and $r_{0}$ are set to $5 \mathrm{~km}$ and 0.99 , respectively. At $d=5 \mathrm{~km}, r$ is equal to $r_{0} \times(1 / \mathrm{exp})$, or 0.364 . When

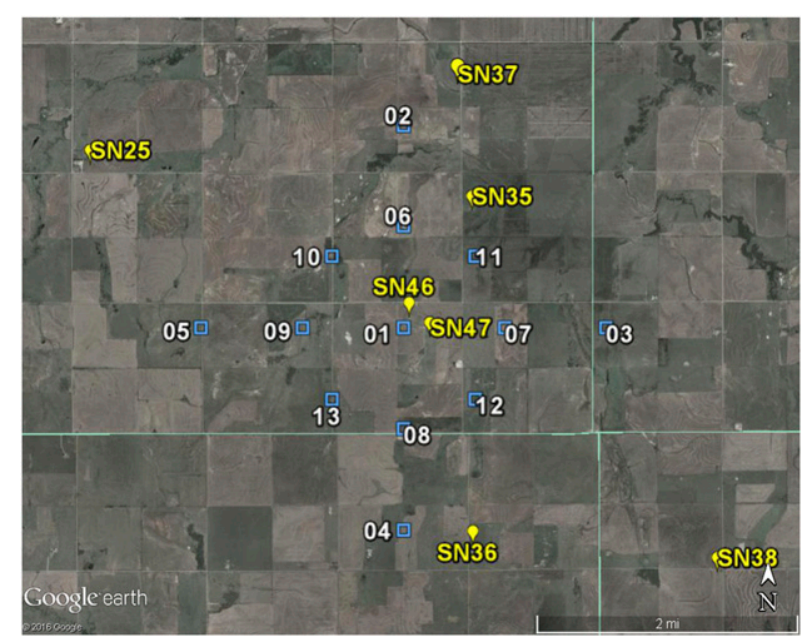

FIG. 1. Areal view (Google Earth) of seven 2DVDs (yellow balloons) and 13 interpolated sites (blue squares) during MC3E in northern Oklahoma. 


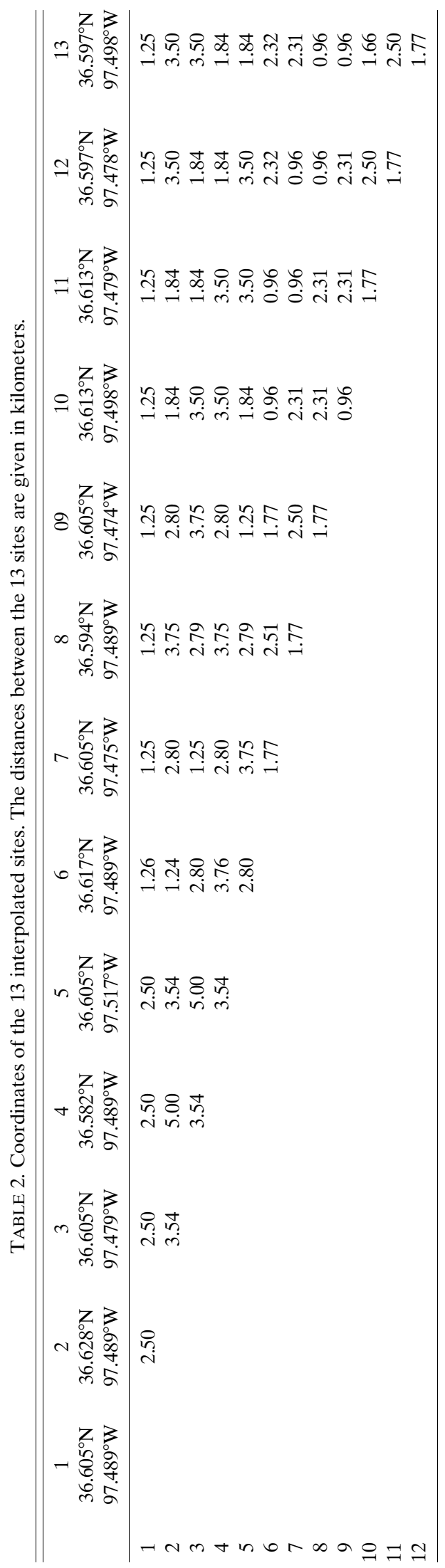

TABLE 3. Sample sizes for four different rainfall thresholds. The minimum rainfall thresholds are applied to areal mean values of rain rate and $\mathrm{Ka}$ - and $\mathrm{Ku}$-band reflectivity fields after interpolation.

\begin{tabular}{lc}
\hline \hline Rainfall threshold & Sample size \\
\hline$R \geq 0.1 \mathrm{~mm} \mathrm{~h}^{-1}$ & 723 \\
$\geq 13 \mathrm{~dB} Z \_\mathrm{Ka}$ & 703 \\
$\geq 13 \mathrm{~dB} Z \_\mathrm{Ku}$ & 698 \\
$\geq 18 \mathrm{~dB} Z \_\mathrm{Ka} \& \mathrm{Ku}$ & 639 \\
\hline
\end{tabular}

$r$ is less than $0.364, d_{0}$ increases with $s_{0}$, and the opposite is true when $r$ is greater than 0.364 . Considering an $r$ value of 0.6 at $2-\mathrm{km}$ distance, $d_{0}$ would be 4 and $8 \mathrm{~km}$ if $s_{0}$ were 1.0 and 0.5 , respectively. Thus, $s_{0}$ plays an important role in determining $d_{0}$ for a given correlation at particular distance.

\section{Raindrop size distribution}

As described in the GPM DPR algorithm (Seto et al. 2013), a normalized gamma distribution is adopted to determine the spatial variability of DSD parameters. The normalized size distribution is expressed as

$N(D)=N_{W} f(\mu)\left(\frac{D}{D_{\text {mass }}}\right)^{\mu} \exp \left[-(4+\mu) \frac{D}{D_{\text {mass }}}\right]$

where $f(\mu)$ is given as a function of the shape parameter $\mu$ :

$$
f(\mu)=\frac{6}{256} \frac{(4+\mu)^{\mu}}{\Gamma(\mu+4)} .
$$

The $D_{\text {mass }}$ and $N_{W}$ are the other two parameters of the normalized gamma distribution. Parameter $D_{\text {mass }}$ is the ratio of the fourth to third moment of the size distribution, while $N_{W}$ is related to liquid water content $W$ and $D_{\text {mass }}$ and is given as

$$
N_{W}=\frac{256}{\pi \rho_{W}} \frac{10^{3} W}{D_{\text {mass }}^{4}}
$$

where $\rho_{w}$ is the density of water. Since $D_{\text {mass }}$ and $W$ are calculated from the observed size distribution, $N_{W}$ is a direct output of the 2DVD observations. The values of $N_{W}$ span nearly five orders of magnitude; therefore, logarithmic values are used to determine its spatial variability.

The shape parameter has a wide range where the bounds are subjectively predetermined. The bounds were -2 and 30 in Tokay and Short (1996) and -4 and 15 in Ulbrich and Atlas (1998). Both studies used the method of moments. The shape parameter is sensitive to the choice of moments and whether or not the truncated moments are used. In this study, the shape parameter 


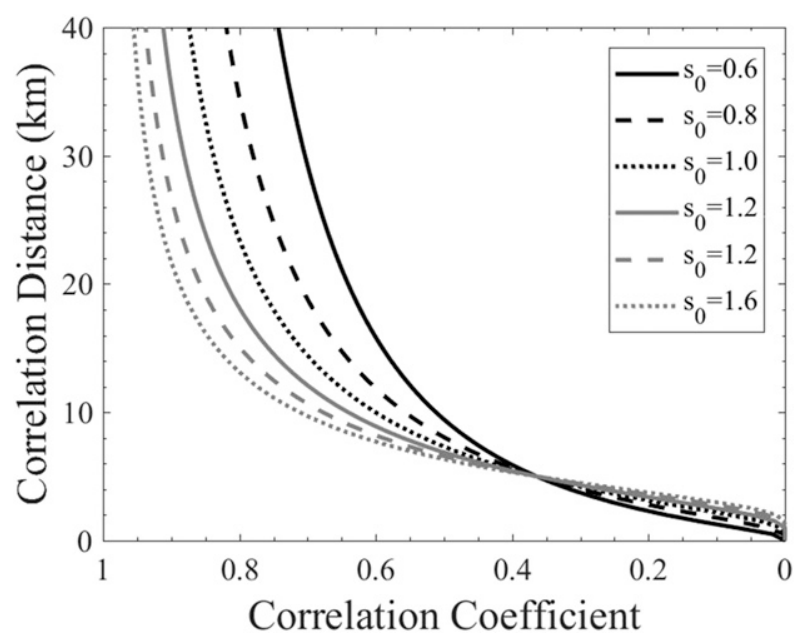

FIG. 2. Dependence of the correlation distance to the correlation coefficient for six prescribed shape parameters at $5-\mathrm{km}$ distance and when the nugget parameter is set to 0.99 .

was determined by minimizing the rain rate difference between the observed size distribution and that computed from a normalized gamma distribution (Tokay and Bashor 2010; Tokay et al. 2016). An initial guess between -2 and 23 with 0.1 increments was the input for the shape parameter when the rain rate is calculated from a gamma distribution.

\section{Integral rain parameters}

In addition to three DSD parameters, the spatial variability of five integral rain parameters is presented in this study. The rain rate $R$ is expressed as

$$
R=\frac{\pi}{6} \int_{D_{\min }}^{D_{\max }} D^{3} v(D) N(D) d D
$$

where $v(D)$ is fall speed of raindrops following Beard (1976). The reflectivity at the Ka and Ku bands are two other rain parameters and are expressed as

$\mathrm{Z} \_\mathrm{Ka}, \mathrm{Ku}=\frac{\lambda^{4}}{\pi^{5}|K|^{2}} \int_{D_{\min }}^{D_{\max }} N(D) \sigma_{b}\left(\lambda_{\mathrm{Ka}, \mathrm{Ku}}, D, T\right) d D$,

where $|K|^{2}$ is the dielectric constant of water, $\lambda$ is the wavelength at the $\mathrm{Ka}(35.5 \mathrm{GHz})$ or $\mathrm{Ku}$ band $(13.8 \mathrm{GHz})$, and $\sigma_{b}$ is the backscattering cross section and is calculated through full Mie theory as a function of $\lambda, D$, and temperature $T$. Since the raindrops look spherical from the top angle, no axis ratios are taken into account. The temperature was specified as $20^{\circ} \mathrm{C}$. The specific attenuations at the $\mathrm{Ka}\left(\mathrm{k} \_\mathrm{Ka}\right)$ and $\mathrm{Ku}$ bands $\left(\mathrm{k} \_\mathrm{Ku}\right)$ are the remaining two rain parameters and are expressed as $\mathrm{k} \_\mathrm{Ka}, \mathrm{Ku}=4343 \int_{D_{\min }}^{D_{\max }} N(D) \sigma_{\mathrm{ext}}\left(\lambda_{\mathrm{Ka}, \mathrm{Ku}}, D, T\right) d D$,

where $\sigma_{\text {ext }}$ is the extinction cross section and is calculated through full Mie theory similar to backscattering cross section.

\section{Inverse distance weighting}

Precipitation products based on point measurements rely on interpolation of the measurements in selected grid spacing. The performance and reliability of interpolation algorithms depends highly on climate, season, and terrain, as well as the instruments' spatial distribution, sampling interval, and density (Dirks et al. 1998; Haberlandt 2007; Porcù et al. 2014). The IDW technique is considered as a baseline algorithm for benchmarking more advanced interpolation techniques that require detailed knowledge of precipitation spatial properties. All available instruments (e.g., 2DVDs) are used to perform the interpolation. A physical parameter (e.g., rain rate) at a desired site is obtained through a weighted average of the same parameter measured by surrounding instruments. The weights are defined as $d^{-\beta}$, where $d$ is the distance between the desired site and each of the surrounding instruments. The exponent $\beta$ has to be determined by considering the measurement accumulation time and precipitation characteristics. A simple and robust choice is to set $\beta=2$, considering that the results of interpolation vary slowly with $\beta$ around this value (Dirks et al. 1998), and this value was used in this study where IDW was applied to a 1-min, bin-by-bin size spectrum for the first time.

The accuracy of the IDW was tested through cross comparison of four physical parameters, $D_{\text {mass }}, \log N_{W}$, $R$, and $\mathrm{Z}_{-} \mathrm{Ku}$, between SN46 and site 1 and between SN47 and site 1 . Site 1 is 0.15 and $0.34 \mathrm{~km}$ from SN46 and SN47, respectively. There were 707 samples where SN46 and SN47 measured $R \geq 0.1 \mathrm{~mm} \mathrm{~h}^{-1}$. Figure 3 reveals that there is excellent agreement between the observed and interpolated parameters. There was also no systematic over- or underestimation of any parameter. Site 1 had a better agreement with SN46 because of its closer distance. The statistics presented in Table 4 confirm the excellent agreement. Bias is the difference of the physical parameter between its interpolated and measured value. We present the percent bias where bias is divided by mean value of the observed parameter. Since the measurement site is considered as a reference, bias and absolute bias are also considered as mean error and mean absolute error. Rain rate was slightly overestimated, with $0.6 \%$ and $1.8 \%$ bias and $4 \%$ and $20 \%$ absolute bias with respect to SN46 and SN47, respectively. 

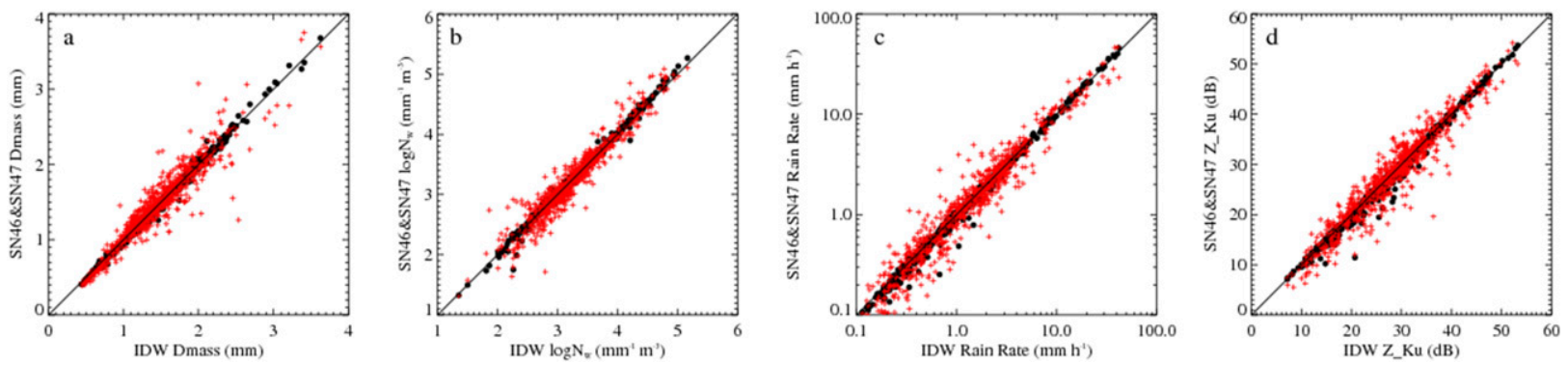

FIG. 3. Comparison of DSD-derived (a) mass-weighted drop diameter, (b) logarithmic normalized intercept parameter, (c) rain rate, and (d) reflectivity at Ku band between 2DVD SN46 (SN47) and IDW interpolated value at site 1. The black circles represent SN46 and red pluses represent SN47-based comparisons.

\section{Probability density function}

PDFs of three parameters of the normalized gamma distribution and five parameters of bulk descriptors of rainfall are presented for four different rain/no-rain thresholds. All eight physical parameters are calculated through averaging their values at 13 interpolation sites. The sample size decreased noticeably from an $R$-based threshold to $Z$-based thresholds, reaching its minimum at the combined $\mathrm{Z} \_\mathrm{Ka}$ and $\mathrm{Z} \_\mathrm{Ku}\left(\mathrm{Z} \_\mathrm{Ka} \& \mathrm{Z} \_\mathrm{Ku}\right)$-based threshold where light rain was eliminated considerably. This can be identified visually at the left tail of the PDF of $D_{\text {mass }}$ and rain parameters (Fig. 4). The PDF of $\log N_{W}$ and $\mu$, on the other hand, had lower percentages at the upper tail for reflectivity-based thresholds. The breadth of the PDF does not show significant differences between the four thresholds for all DSD and rain parameters.

Table 5 presents the mean, standard deviation, and median of eight physical parameters for $R$ - and Z_Ka\&Z_Ku-based thresholds. The table also includes the maximum values of each variable for areal mean and individual site. The difference between the two maxima signifies the variability within the footprint. The maximum value of $D_{\text {mass }}$ was $3.27 \mathrm{~mm}$ for an areal mean but is $3.63 \mathrm{~mm}$ at the site. For $R$, the areal mean was $28.8 \mathrm{~mm} \mathrm{~h}^{-1}$, while one of the sites reported $70.1 \mathrm{~mm} \mathrm{~h}^{-1}$. It should be reminded that these maximum values are relatively high globally due to the nature of rain during MC3E. Spring and summertime continental rain often includes heavy bursts in Oklahoma. The $\mathrm{Z}_{-} \mathrm{Ku}$ of $56.3 \mathrm{~dB} Z$ at a site was another indicator of a heavy burst.
The maximum $\mathrm{Z} \_\mathrm{Ku}$ for an areal mean was $5.6 \mathrm{dBZ}$ lower than that at a site.

The mean and median of $D_{\text {mass }}$ and rain parameters were higher at the $\mathrm{Z} \_\mathrm{Ka} \& \mathrm{Z} \_\mathrm{Ku}$ threshold than the $R$-based threshold due to elimination of light rain samples. The medians were considerably lower than the mean in the presence of secondary peaks at lower values in the PDF of $R, \mathrm{Z} \_\mathrm{Ku}, \mathrm{k} \_\mathrm{Ku}$, and $\mathrm{k} \_\mathrm{Ka}$. For $R$, median and mean values were 1.9 and $3.1 \mathrm{~mm} \mathrm{~h}^{-1}$, respectively, at the $\mathrm{Z} \_\mathrm{Ka} \& \mathrm{Z} \_\mathrm{Ku}$ threshold. While, light-to-moderate rain $\left(R<2 \mathrm{~mm} \mathrm{~h}^{-1}\right)$ dominated the sample and lowered the median, moderateto-heavy $\left(R \geq 5 \mathrm{~mm} \mathrm{~h}^{-1}\right)$ rain provided a noticeable contribution and raised the mean value. For the $\mathrm{Z} \_\mathrm{Ka} \& \mathrm{Z} \_\mathrm{Ku}$ threshold, approximately $13 \%$ and $7 \%$ of the observations had $R \geq 5 \mathrm{~mm} \mathrm{~h}^{-1}$ and $R \geq 10 \mathrm{~mm} \mathrm{~h}^{-1}$, respectively.

Moderate-to-heavy rain in the southern Great Plains receives a relatively high percent of contribution from large drops ( $>3 \mathrm{~mm}$ in diameter). Indeed, the world's largest drop ever observed by a disdrometer, $9.7 \mathrm{~mm}$ in diameter, occurred during MC3E (Gatlin et al. 2015). It is assumed that melted graupel near the surface created this giant raindrop. The presence of large drops resulted in $14 \%$ of the observations with $D_{\text {mass }} \geq 2.0 \mathrm{~mm}$ at the Z_Ka\&Z_Ku threshold. For the same threshold, $11 \%$ and $16 \%$ of the observations had $\mathrm{Z} \_\mathrm{Ku} \geq 40 \mathrm{dBZ}$ and $\mathrm{k} \_\mathrm{Ka} \geq$ $1 \mathrm{~dB} \mathrm{~km}^{-1}$, respectively. The MC3E dataset exhibited drastically different properties than the preceding study conducted at the mid-Atlantic coastal site of Wallops Island, Virginia, where virtually no observations of $R \geq$ $10 \mathrm{~mm} \mathrm{~h}^{-1}, D_{\text {mass }} \geq 2.0 \mathrm{~mm}$, and $\mathrm{Z}_{-} \mathrm{Ku} \geq 40 \mathrm{dBZ}$ occurred (Tokay et al. 2016).

TABLE 4. Percent bias and percent absolute bias of four parameters between site 1 and SN46 and between site 1 and SN47. SN46 and SN47 are considered as a reference.

\begin{tabular}{lcccr}
\hline \hline Parameter & Bias (\%) SN46 & Absolute bias (\%) SN46 & Bias (\%) SN47 & Absolute bias (\%) SN47 \\
\hline$D_{\text {mass }}$ & 0.8 & 1.8 & -0.4 & 7.3 \\
$\log N_{W}$ & -0.3 & 0.9 & 0.4 & 3.7 \\
$R$ & 0.6 & 4.0 & 1.8 & 20.0 \\
$Z_{-} \mathrm{Ku}$ & 1.0 & 1.8 & 0.9 & 6.9 \\
\hline
\end{tabular}



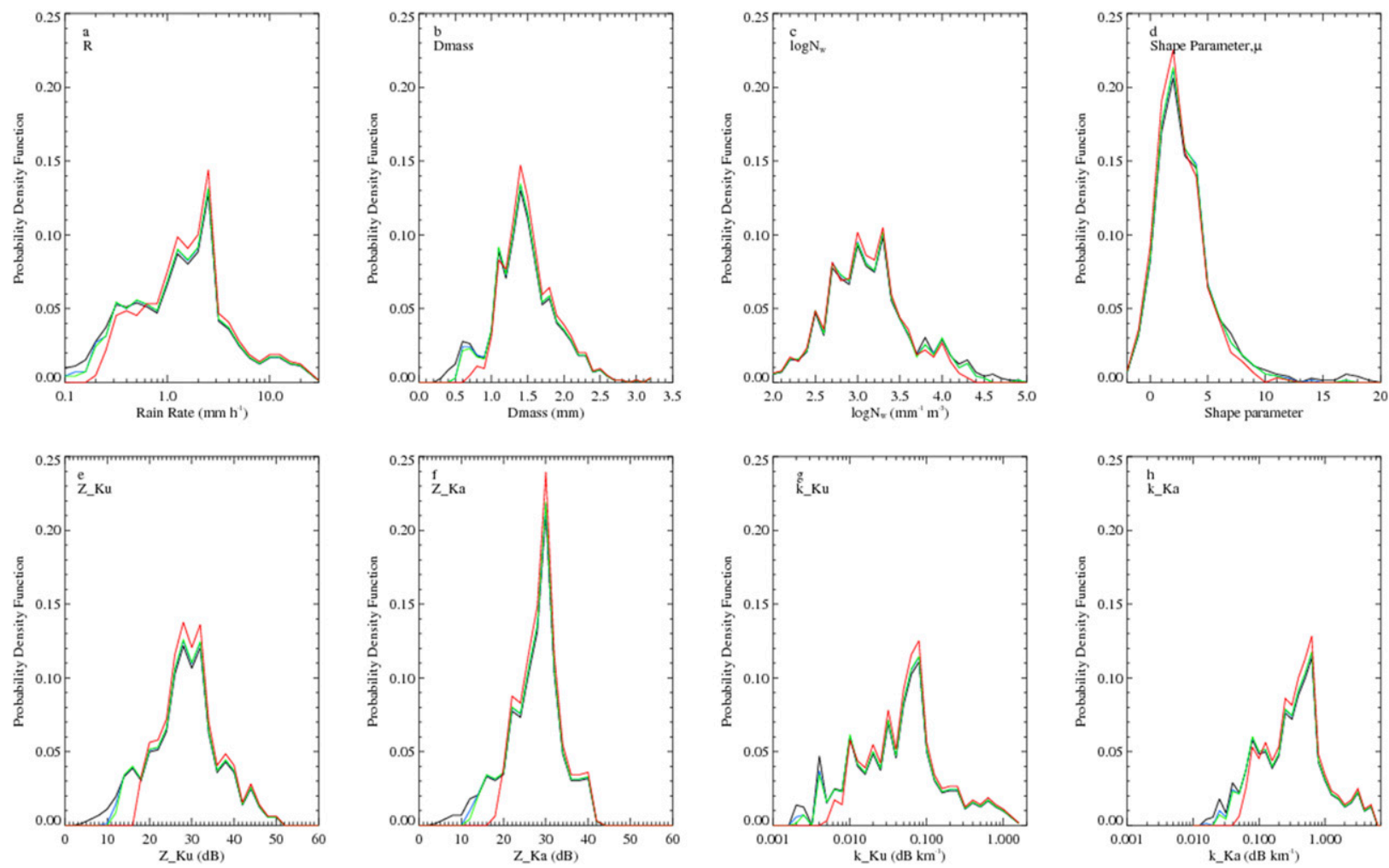

FIG. 4. PDFs of (a) rain rate, (b) mass-weighted diameter, (c) logarithmic normalized intercept parameter, (d) shape parameter, (e) reflectivity at $\mathrm{Ku}$ band, (f) reflectivity at $\mathrm{Ka}$ band, (g) specific attenuation at $\mathrm{Ku}$ band, and (h) specific attenuation at Ka band for $R$ (black), Z_Ka (blue), Z_Ku (green), and Z_Ka\&Z_Ku (red) rain/no-rain thresholds.

The maximum values of $\log N_{W}$ and $\mu$ were slightly lower at the Z_Ka\&Z_Ku threshold compared to the $R$ threshold. Parameter $N_{W}$ is sensitive to the drop concentration, which is mainly contributed by small drops
$(<1 \mathrm{~mm}$ in diameter). The 2DVD has a reduced detection of drops less than $\sim 0.5 \mathrm{~mm}$ (Tokay et al. 2013) resulting in an underestimation of $N_{W}$. The size spectrum that has the highest $N_{W}$ does not necessary

TABLE 5. Areal mean, standard deviation, and median values of eight physical parameters for the $R$ (upper row) and $\mathrm{Z} \_\mathrm{Ka} \& \mathrm{Z} \_\mathrm{Ku}$ (lower row) thresholds. The areal mean and individual site maximum values of the same parameters are also given the same thresholds. Note that maximum values are the same for both thresholds except $\log N_{W}$.

\begin{tabular}{|c|c|c|c|c|c|}
\hline Parameter & Mean & Standard deviation & Median & Max (areal mean) & $\operatorname{Max}($ site) \\
\hline \multirow[t]{2}{*}{$D_{\text {mass }}(\mathrm{mm})$} & 1.49 & 0.44 & 1.48 & 3.27 & 3.63 \\
\hline & 1.58 & 0.38 & 1.51 & & \\
\hline \multirow[t]{2}{*}{$\log N_{W}\left(\mathrm{~mm}^{-1} \mathrm{~m}^{-3}\right)$} & 3.58 & 3.88 & 3.14 & 4.96 & 5.17 \\
\hline & 3.38 & 3.49 & 3.12 & 4.37 & 4.56 \\
\hline \multirow[t]{2}{*}{ Shape parameter $\mu$} & 3.6 & 2.9 & 3.0 & 19.0 & 23.1 \\
\hline & 3.1 & 2.1 & 2.7 & & \\
\hline \multirow[t]{2}{*}{$R\left(\mathrm{~mm} \mathrm{~h}^{-1}\right)$} & 2.8 & 4.1 & 1.5 & 28.8 & 70.1 \\
\hline & 3.1 & 4.2 & 1.9 & & \\
\hline \multirow[t]{2}{*}{ Z_Ku (dB) } & 36.6 & 11.2 & 29.3 & 50.7 & 56.3 \\
\hline & 37.1 & 9.0 & 30.4 & & \\
\hline \multirow[t]{2}{*}{ Z_Ka (dB) } & 32.2 & 7.8 & 29.4 & 42.2 & 44.7 \\
\hline & 32.7 & 5.6 & 30.1 & & \\
\hline \multirow[t]{2}{*}{$\mathrm{K} \_\mathrm{Ku}\left(\mathrm{dB} \mathrm{km}{ }^{-1}\right)$} & 0.12 & 0.21 & 0.05 & 1.61 & 4.26 \\
\hline & 0.13 & 0.22 & 0.06 & & \\
\hline \multirow[t]{2}{*}{ K_Ka $\left(\mathrm{dB} \mathrm{km}^{-1}\right)$} & 0.66 & 0.95 & 0.37 & 6.31 & 12.55 \\
\hline & 0.74 & 0.98 & 0.45 & & \\
\hline
\end{tabular}


correspond to moderate-to-heavy rain. During MC3E, the highest areal mean and site $N_{W}$ corresponded to the observation where both $\mathrm{Z} \_\mathrm{Ka}$ and $\mathrm{Z} \_\mathrm{Ku}$ were less than $18 \mathrm{~dB} Z$. Therefore, this observation was eliminated at the $\mathrm{Z} \_K a \& Z \_K u$ threshold, resulting in a lower maximum $N_{W}$ at this threshold. In fact, high $N_{W}$ values were frequently observed below the $\mathrm{Z} \_\mathrm{Ka} \& \mathrm{Z} \_\mathrm{Ku}$ threshold, resulting in lower median and mean $N_{W}$.

The presence of a large drop resulted in broader size distributions with a relatively small shape parameter. The mean and median shape parameters were significantly smaller than those observed at Wallops Island, Virginia (Tokay et al. 2016). The elimination of light rain observations, which typically correspond to a shallow size distribution with a relatively high shape parameter, lowered the mean and median shape parameter at the Z_Ka\&Z_Ku threshold. The shape parameter was set to 2 in the GPM Combined (Grecu et al. 2016) and 3 in the GPM DPR (Seto et al. 2013) algorithms. Interestingly, the PDF of the shape parameter exhibited a sharp peak where $80 \%$ of the observations fell between 0 and 5, with the peak between 2 and 3 at the $Z_{-} K a \& Z \_K u$ threshold. It should be noted that a gamma distribution is not always the best choice for modeling the observed size distribution. For example, a drop-breakup-induced size distribution typically exhibits a bimodal distribution (D'Adderio et al. 2015), with the result being gamma fits that result in artificially high shape parameters.

\section{Spatial variability}

\section{a. Correlation coefficient}

Correlation coefficients for eight parameters were calculated between 13 interpolated sites for four different rain/no-rain thresholds. Figure 5 shows the 78 paired correlations for the $R$ threshold only, but fitted curves and corresponding parameters of the exponential function are given for all four thresholds. Because of the symmetry of the selected interpolated sites, there were multiple correlations at a given distance. The center point, site 1, for instance, was a distance of $1.25 \mathrm{~km}$ from eight different sites. The correlations differed substantially at the same distance as a result of storm orientation even though the database is a combination of multiple events.

Considering correlations between site 1 and surrounding sites, the variability of $R$ was greatest in the northeast, where correlations fell below 0.84 at $1.25-\mathrm{km}$ distance (Fig. 5a). The correlations were also below 0.90 to the north but remained around $0.94-0.97$ for the other directions at the same distance. At $2.5-\mathrm{km}$ distance, the correlations were below 0.60 and 0.70 at south and north directions, respectively, but were above 0.86 and 0.91 at west and east directions, respectively. This demonstrates a nature of rainfall variability. The degree of rainfall uniformity is highly different from one event to another as well as within a given event.

The variability of $D_{\text {mass }}$ was greatest toward the north and northeast, where correlations fell below 0.80 and 0.90 at 5.0- and 2.5-km distances, respectively (Fig. 5b). Interestingly, the variability of $D_{\text {mass }}$ was the least toward the east and southeast, where correlations were above 0.90 and 0.95 at $5.0-$ and $2.5-\mathrm{km}$ distances, respectively. The correlations of $\log N_{W}$ had two contrasting patterns at $1.25-$ and $2.5-\mathrm{km}$ distances (Fig. 5c). At $1.25 \mathrm{~km}$, the correlations remained between 0.90 and 0.95 , while they were below 0.60 and 0.83 to the south and north, respectively, at $2.5-\mathrm{km}$ distance. For the shape parameter, the correlations were low but did not have significant directional differences, remaining between 0.70 and 0.76 at $1.25-\mathrm{km}$ distance (Fig. 5d). The correlations were relatively lower, $0.62-0.69$, but exceptionally low to the south, 0.49 at $2.5 \mathrm{~km}$.

The variability of $\mathrm{Z} \_\mathrm{Ku}$ and $\mathrm{Z} \_\mathrm{Ka}$ exhibited similar features (Figs. 5e,f). The correlations were high, 0.94-0.96, and did not have a directional dependence at $1.25-\mathrm{km}$ distance, while the high uniformity was also valid at $2.5 \mathrm{~km}$, where the correlations were $0.84-0.86$, except that one relatively higher correlation of 0.93 was found to the east. The variability of $\mathrm{k} \_\mathrm{Ku}$ and $\mathrm{k} \_\mathrm{Ka}$ had similar features, except that the correlations were relatively higher at k_Ka band (Figs. 5g,h). Correlations of $\mathrm{k} \_\mathrm{Ku}$ were below 0.80 and 0.88 at the northeast and north directions, respectively, while they were above 0.90 for other directions at $1.25-\mathrm{km}$ distance. The correlations of $\mathrm{k} \_\mathrm{Ku}$ were also remarkably lower toward the south (0.54) and north (0.65).

A three-parameter exponential function fit to the observed correlations revealed several features. The directional changes in precipitation patterns had relatively less impact on $Z_{-} \mathrm{Ku}, \mathrm{Z} \_\mathrm{Ka}$, and $D_{\text {mass }}$ fields, where correlations remained above 0.75 regardless of distance in the $R$ threshold database. This resulted in higher $d_{0}$ in the range from 24 to $29 \mathrm{~km}$. The corresponding $s_{0}$ was in a range of 1.18-1.38 and the RMSE was the lowest $(<0.05)$ among all DSD and rain parameters.

The correlations at a given distance were more sensitive to the choice of threshold for these three fields, except that correlations were about the same for the Z_Ka and Z_Ku threshold database (not shown). The parameters of the exponential function were therefore very close to each other for these two thresholds. The correlations between the north and south directions 

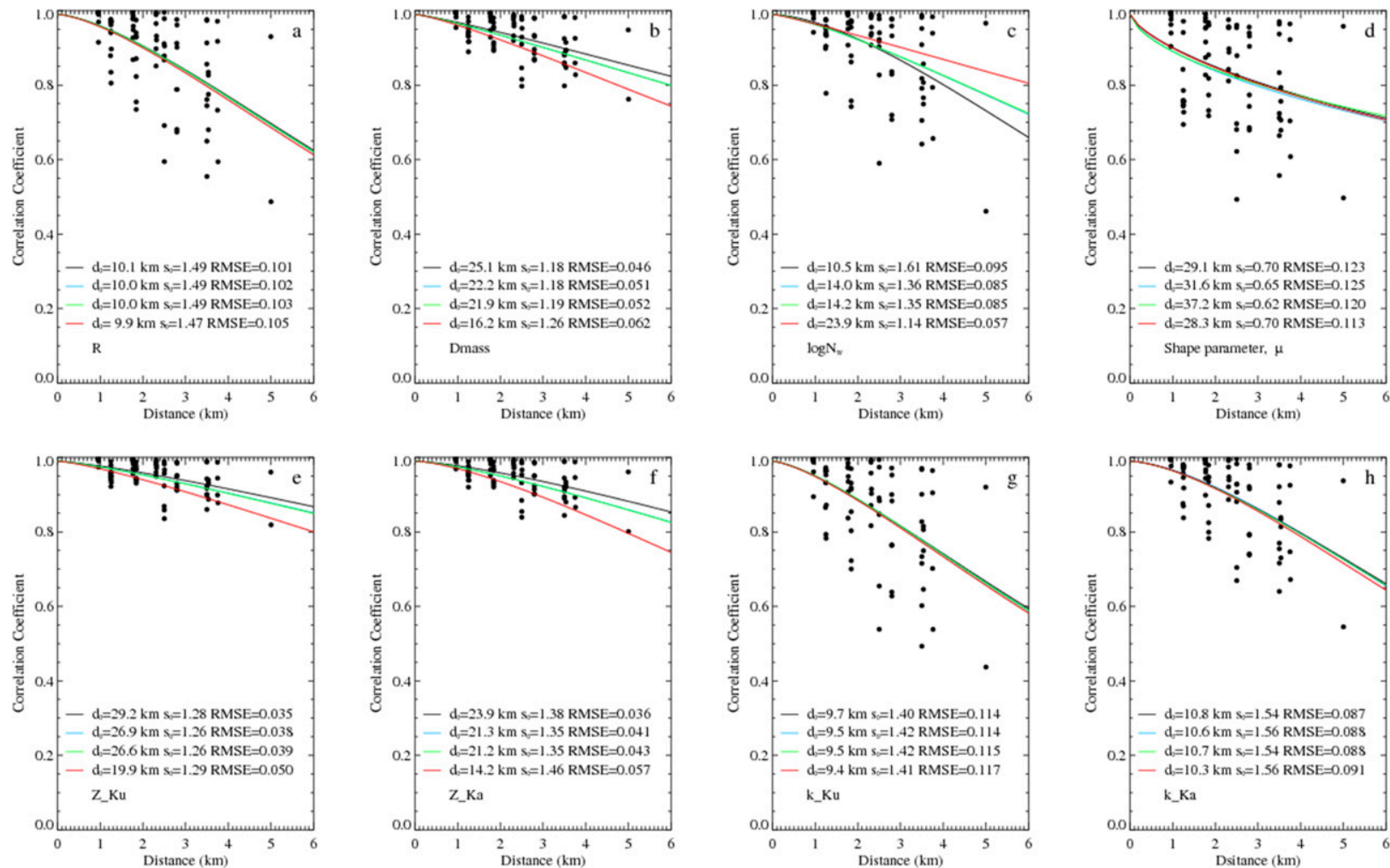

FIG. 5. Correlation coefficients of (a) rain rate, (b) mass-weighted diameter, (c) logarithmic normalized intercept parameter, (d) shape parameter, (e) reflectivity at $\mathrm{Ku}$ band, (f) reflectivity at Ka band, (g) specific attenuation at $\mathrm{Ku}$ band, and (h) specific attenuation at Ka band are depicted with black circles for 78 pairs. The best fit of the three-parameter exponential function is also shown with curves for $R$ (black), Z_Ka (blue), Z_Ku (green), and Z_Ka\&Z_Ku (red) rain/no-rain thresholds. Please note that blue and green curves are indistinguishable. The correlation distance, shape parameter of exponential fit, and RMSE are also given for each fit.

were significantly lower than the correlations between the east and west directions, especially at $5 \mathrm{~km}$ distance at the $\mathrm{Z} \_K u \& Z \_K a$ threshold (not shown), resulting in relatively higher RMSE in the exponential fit. The $d_{0}$ was lower and $s_{0}$ was higher with respect to the three other thresholds for these three fields.

The correlations at a given distance were not sensitive to the choice of threshold for the $R, \mathrm{k} \_\mathrm{Ku}$, and $\mathrm{k} \_\mathrm{Ka}$ fields. The parameters of the exponential function were therefore very close to each other for all four thresholds for these three fields. At the same time, there were substantial differences in correlations at a given distance in these fields. The correlation of $R$, for instance, ranged from 0.93 to 0.48 at a $5-\mathrm{km}$ distance for a given $R$ threshold. This resulted in high RMSE $(>0.08)$ for these three fields.

The correlations of $\log N_{W}$ also showed sensitivity to the choice of threshold but in reverse order. That is, the differences in correlations between the east-west and north-south directions were more sensitive to the $R$ threshold and the least sensitive to the $\mathrm{Z} \_\mathrm{Ku} \& \mathrm{Z} \_\mathrm{Ka}$ threshold at $5-\mathrm{km}$ distance. The exponential fits were then lowest and had the highest RMSE at the Z_Ku\&Z_Ka and $R$ thresholds, respectively. The $d_{0}$ was highest and $s_{0}$ was lowest at the $R$ threshold. As shown in probability and cumulative distributions of $\log N_{W}$, the elimination of light rain samples due to $\mathrm{Z} \_$Ka- and $\mathrm{Z} \_K u$-based thresholds corresponded to the samples that had higher $\log N_{W}$, which were typically not well correlated with other sites within the footprint.

The correlations of the gamma distribution shape parameter were not sensitive to the choice of threshold but highly sensitive to the direction. The RMSE of the exponential fit was therefore the greatest $(>0.11)$ among all fields. The $s_{0}$ was lower than 1.0 only for this field and corresponding $d_{0}$ was high, $28-37 \mathrm{~km}$ even though the correlations were less than 0.8 for nearly half of the observations.

\section{b. Coefficient of variation}

The CV is the ratio of standard deviation to the mean value and is preferable to the standard deviation since it is a normalized quantity. It has been employed to categorize the variability of rainfall in gauge-based studies 
(Habib et al. 2009; Tokay and Öztürk 2012). It has also been used in determining spatial variability of total concentration, $D_{\text {mass }}$, and $R$ (Jaffrain et al. 2011). In this study, the mean value and its standard deviation of eight physical parameters were calculated among 13 sites for each sample in linear space. Similar steps were also done for calculating $\mathrm{Z} \_\mathrm{Ku}$ and $\mathrm{Z} \_\mathrm{Ka}$. The $\mathrm{CV}$ of the physical parameters was then presented as a function of areal average rain rate for the $R$ threshold and as a function of Z_Ku for the Z_Ku\&Z_Ka threshold (Fig. 6). The CV of the parameters exhibited similar distributions for the $\mathrm{Z} \_\mathrm{Ka}$ and $\mathrm{Z} \_\mathrm{Ku}$ thresholds and was not shown.

Table 6 presents the number of observations (in percent) of areal mean values of three DSDs and five integral rain parameters that were classified into five $\mathrm{CV}$ classes for the $R$ and $\mathrm{Z} \_K u \& Z \_K a$ thresholds. Five $C V$ classes represent the degree of uniformity of the parameter from highly uniform $(\mathrm{CV} \leq 0.25)$ to extremely variable $(\mathrm{CV}>1.00)$ classes. The remaining three classes may be called mostly uniform $(0.25<\mathrm{CV} \leq 0.5)$, moderately variable $(0.5<\mathrm{CV} \leq 0.75)$, and highly variable $(0.75<\mathrm{CV} \leq 1.0)$.

All physical parameters had $\mathrm{CV} \leq 1.25$, except the shape parameter of the modeled gamma distribution. The vast majority of $R$ had $\mathrm{CV} \leq 0.5$, and only $8 \%$ of the observations showed moderate to extreme variability $(\mathrm{CV}>0.5)$. There were two samples where the $\mathrm{CV}$ of $R$ exceeded 1.0. These samples corresponded to $\mathrm{Z} \_\mathrm{Ku}$ of 41.2 and $36.8 \mathrm{~dB}$ and $R$ of 3.2 and $1.6 \mathrm{~mm} \mathrm{~h}^{-1}$ (Figs. 6a, b), and all 13 sites reported rainfall in both samples.

Among all physical parameters, $D_{\text {mass }}$ was the most uniform across the range of $R$ and $Z \_K u$ values (Figs. 6c, d). Considering the $Z \_K u \& Z \_K a$ threshold, there were two outliers with CVs of 0.7 and 0.8 . These outliers occurred in back-to-back minutes during a deep convective event where one and two sites did not report rainfall. The corresponding $R$ values were 0.34 and $0.22 \mathrm{~mm} \mathrm{~h}^{-1}$ and $\mathrm{Z} \_\mathrm{Ku}$ values were 23 and $20 \mathrm{~dB}$, respectively.

The CV of $N_{W}$ fell mostly in a highly uniform class, but a significant number of observations were also under a mostly uniform class. There were three samples that exceeded a CV of 1.0 (Figs. 6e,f). Among those, the highest $\mathrm{CV}$ of $N_{W}$ occurred during light rain where $R$ was $0.34 \mathrm{~m} \mathrm{~h}^{-1}$ and $\mathrm{Z} \_\mathrm{Ku}$ was $27.7 \mathrm{~dB}$ and when all sites were reporting rainfall. This demonstrates that light rain with abundant small drops and lack of large drops could result in high variability of $N_{W}$ within a DPR pixel.

The shape parameter of the gamma distribution is sensitive to the width of the distribution, which is driven by the presence or absence of large drops. It is also sensitive to the method of derivation. High shape parameters are often assigned when the size spectra have a slope where concentration decreases more than four orders of magnitude between $1.0-$ and $2.5-\mathrm{mm}$ diameters, followed by gradual decrease toward higher diameters (D'Adderio et al. 2015). The gamma distribution may not be the best choice for these size distributions, resulting in extreme variability within the footprint. Indeed, this was the case for $9 \%$ of the sample (Figs. 6g,h). A CV greater than 2 was observed over a dozen of samples (not shown). In the majority of cases, the $\mathrm{CV}$ of the shape parameter was less than 0.5 though.

The CV of $\mathrm{Z}_{-} \mathrm{Ku}$ was mostly highly uniform, but a significant number of samples fell also into the mostly uniform class (Figs. 6i,j). While the $\mathrm{CV}$ of $\mathrm{Z}_{-} \mathrm{Ku}$ was observed as less than $12 \%$ for each of the remaining three classes, nonuniform samples were visible across all $R$ and $\mathrm{Z}_{-} \mathrm{Ku}$. The class of extreme variability, for instance, had 36 samples for both $R$ - and Z_Ku\&Z_Kabased thresholds. For the $\mathrm{CV}$ of $\mathrm{Z} \_\mathrm{Ka}$, most of the observations fell also in the highly and mostly uniform classes, and the remaining three classes had fewer samples than the $\mathrm{CV}$ of $Z_{-} \mathrm{Ku}$ (Figs. 6k,1). The dynamic range of $Z_{-} K u$ and $Z_{-} \mathrm{Ka}$ is more than four orders of magnitude in linear space. This plays an important role in the variability of these parameters within the DPR footprint.

The $\mathrm{CV}$ of $\mathrm{k} \_\mathrm{Ku}$ fell mostly into the highly uniform class, and the majority of the database had CVs less than 0.5 (Figs. $6 \mathrm{~m}, \mathrm{n}$ ). Approximately $10 \%-11 \%$ of the sample was classified as moderate and high variability. There were also eight samples where CV exceeded 1.0. Among those, two samples had CVs of 1.29 and 1.36, corresponding to $R$ values of 3.2 and $1.6 \mathrm{~mm} \mathrm{~h}^{-1}$ and Z_Ku values of 41.2 and $36.8 \mathrm{~dB}$, respectively. These two samples also had CV $>1.0$ for k_Ka (Figs. 6o,p). The $\mathrm{CV}$ of $\mathrm{k} \_\mathrm{Ka}$ had similar features as the $\mathrm{CV}$ of $\mathrm{k} \_\mathrm{Ku}$, except that a higher percent of the samples were in the highly uniform class and there were fewer samples in the other four categories.

\section{Discussion}

A key motivation of this study was to evaluate NUBF, which is a complex problem and is well beyond the horizontal spatial variability within the DPR footprint at the single ground level. Grecu et al. (2016) presented the combined algorithm of the GPM mission and pointed out that the systematic differences in NS and MS precipitation estimates are larger for convective rain over land and strongly depend on the NUBF parameterization. They also mentioned that simulated $\mathrm{Z}_{-} \mathrm{Ka}$ was significantly and systematically lower than observed Z_Ka, resulting in erroneous DSD adjustments. A methodology to account for NUBF is therefore necessary 

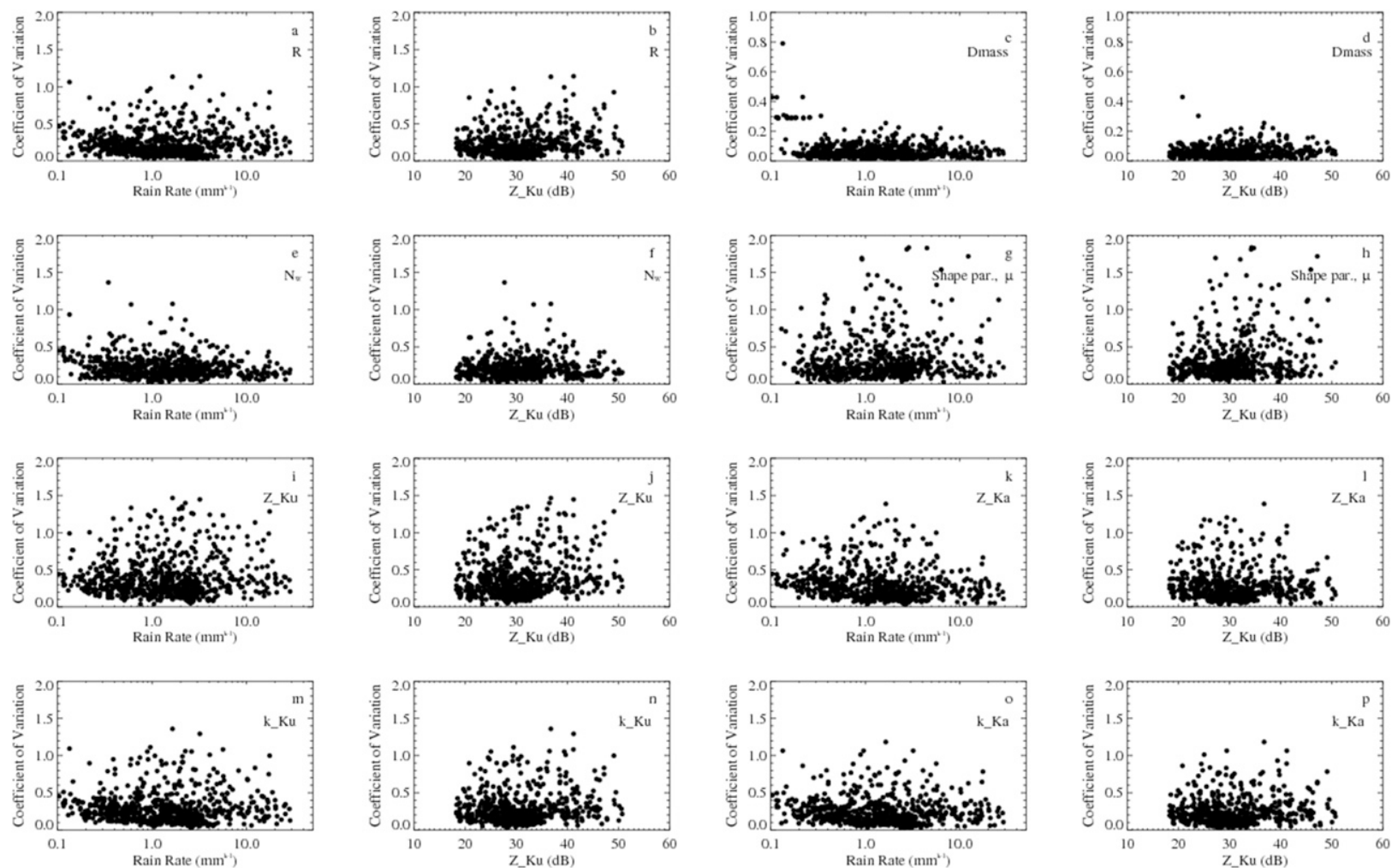

FIG. 6. CVs of (a),(b) rain rate; (c),(d) mass-weighted diameter; (e),(f) logarithmic normalized intercept parameter; (g),(h) shape parameter; (i),(j) reflectivity at $\mathrm{Ku}$ band; (k),(l) reflectivity at $\mathrm{Ka}$ band; (m),(n) specific attenuation at Ku band; and (o),(p) specific attenuation at $\mathrm{Ka}$ band are depicted as functions of areal mean rain rate for the $R$ threshold and reflectivity at Ku band for the $\mathrm{Z} \_\mathrm{Ka} \& \mathrm{Z}$ $\mathrm{Ku}$ threshold.

to mitigate large errors in the $N_{W}$ and precipitation rate estimates derived from DPR observations. A statistical model used by Grecu et al. (2016) requires the correlation distance of $N_{W}$, which is an output of this study. The NUBF parameterization that has been implemented in the combined algorithm uses statistically generated subfootprint profiles of $\mathrm{Z}_{-} \mathrm{Ku}$ that match the observed $\mathrm{Z}_{-} \mathrm{Ku}$ profile when it is averaged. Although this study does not encounter the vertical variability, it can still be a reference for generating the subfootprint Z_Ku.
In a previous study, Iguchi et al. (2000, 2009) recognized the NUBF as a significant source of error in retrieving precipitation from the TRMM precipitation radar and proposed a correction for this, which involves the $\mathrm{CV}$ of the attenuation coefficient. The surface reference technique (SRT) is a method to determine the path attenuation along a radar beam. The SRT relies on the difference in surface returns outside and within the rain area (Meneghini and Liao 2013). This path attenuation estimate is also subject to errors caused by NUBF, and there have been several studies to mitigate

TABLE 6. Percent occurrence of areal mean for three DSDs and five integral rain parameters for five different classes of degree of uniformity for the $R$ (first number) and $\mathrm{Z} \_\mathrm{Ka} \& \mathrm{Z} \_\mathrm{Ku}$ (second number) thresholds. The degree of uniformity was determined through $\mathrm{CV}$ intervals ranging from highly uniform $(\mathrm{CV} \leq 0.25)$ to extremely variable $(\mathrm{CV}>1.00)$. The remaining three classes are mostly uniform $(0.25 \leq \mathrm{CV}<0.50)$, mostly variable $(0.50 \leq \mathrm{CV}<0.75)$, and highly variable $(0.75 \leq \mathrm{CV}<1.00)$.

\begin{tabular}{|c|c|c|c|c|c|c|c|c|}
\hline $\mathrm{CV}$ & $R$ & $D_{\text {mass }}$ & $N_{W}$ & $\mu$ & $\mathrm{Z} \_\mathrm{Ku}$ & Z_Ka & k_Ku & K_Ka \\
\hline$\leq 0.25$ & $0.664 ; 0.689$ & $0.968 ; 0.995$ & $0.687 ; 0.725$ & $0.532 ; 0.563$ & $0.367 ; 0.390$ & $0.530 ; 0.581$ & $0.550 ; 0.570$ & $0.651 ; 0.685$ \\
\hline $0.25-0.50$ & $0.256 ; 0.227$ & $0.030 ; 0.005$ & $0.270 ; 0.238$ & $0.261 ; 0.273$ & $0.404 ; 0.372$ & $0.339 ; 0.296$ & $0.331 ; 0.302$ & $0.267 ; 0.228$ \\
\hline $0.50-0.75$ & $0.058 ; 0.061$ & $0.000 ; 0.000$ & $0.033 ; 0.028$ & $0.090 ; 0.089$ & $0.118 ; 0.117$ & $0.075 ; 0.066$ & $0.066 ; 0.070$ & $0.055 ; 0.058$ \\
\hline $0.75-1.00$ & $0.018 ; 0.020$ & $0.001 ; 0.000$ & $0.006 ; 0.005$ & $0.030 ; 0.033$ & $0.062 ; 0.064$ & $0.041 ; 0.041$ & $0.040 ; 0.045$ & $0.019 ; 0.022$ \\
\hline$>1.00$ & $0.004 ; 0.003$ & $0.000 ; 0.000$ & $0.004 ; 0.005$ & $0.087 ; 0.096$ & $0.050 ; 0.056$ & $0.015 ; 0.017$ & $0.012 ; 0.013$ & $0.007 ; 0.006$ \\
\hline
\end{tabular}


this effect in estimates of both path attenuation and attenuation-corrected reflectivities (Takahashi et al. 2006; Short et al. 2012, 2015; Meneghini et al. 2015). Although these studies show some reduction in the error, NUBF continues to be a significant error source for retrievals over storm cells with strong gradients in precipitation. Recently, DPR algorithm developers used DPR measurements to determine the interpixel spatial variability and then assigned the same variability (e.g., CV) to intrafootprint scales (R. Meneghini 2016, personal communication). This study may be used as a reference for the expected range of variability within a DPR pixel.

Considering ground-based validation studies, the evaluation of NUBF due to path-integrated attenuation requires scanning and/or vertically pointing radar to couple observed horizontal variability to vertical variability and microphysical processes. Also, NUBF studies conducted over GPM passive microwave imager (GMI) instantaneous fields of view (IFOV), which are coarser than the DPR footprint, require an even larger disdrometer array or radar dataset to examine threedimensional variability. The IFOV depends on the choice of microwave channel used in a retrieval algorithm but an effective spatial resolution of $15 \mathrm{~km}$, close to the resolution of the $37-\mathrm{GHz}$ channel of the GMI, has been identified for level 1 requirements of the GPM ground validation program.

\section{Conclusions}

Spatial variability of DSD is investigated through a network of seven 2DVDs operated during MC3E in northern Oklahoma. Special attention is given to NUBF within the DPR footprint. The MC3E 2DVD dataset was unique in its use for the study of heavy midlatitude continental showers but was somewhat limited in its application for event-based or even a separate convective and stratiform precipitation-based study. The dataset also included a very small sample of rain intermittence. Since the 2DVDs were randomly distributed and a number of the units were displaced from each other by distances longer than the approximate diameter of the DPR footprint, the DSDs were interpolated bin-by-bin to a grid of 13 points through inverse distance weighting. Very good agreement was found for selected DSD and rain parameters that were calculated from interpolated and observed DSDs, and the interpolated sites were distanced equally covering the 5-km diameter of the DPR footprint adequately.

Although the database was a combination of numerous events, there were systematic differences in correlations at the same distances. Correlations of rain rate, for instance, only decreased below 0.90 in the north and northeast direction for the $R$ threshold at $1.25-\mathrm{km}$ distance. The directional differences in correlation were evident in other DSD and rain parameters and reflected the important role of storm orientation in spatial variability. The decrease of correlations with distance was also evident in all eight parameters, but it occurred at different magnitudes at different rain/norain thresholds among different parameters. The correlations at a maximum separation distance of $5 \mathrm{~km}$ were much lower in the north-south direction than the east-west direction, resulting in high RMSE for all parameters except for $D_{\text {mass }}, Z_{-} \mathrm{Ku}$, and $\mathrm{Z}_{-} \mathrm{Ka}$, all of which had considerably higher correlations in the north-south direction. The correlations of these three fields were sensitive to the choice of rain threshold, resulting in noticeable differences in correlation distances. The correlation of $\log N_{W}$ was also sensitive to the rain threshold but elimination of light rain due to reflectivity-based thresholds removed samples of high $\log N_{W}$, resulting in higher correlations and raising correlation distances, especially for the $\mathrm{Z} \_\mathrm{Ka} \& \mathrm{Z} \_\mathrm{Ku}$ threshold.

The CV of DSD and integral rain parameters was mostly confined within one or two categories of $\mathrm{CV}$ across the areal average of $R$ and $\mathrm{Z}_{-} \mathrm{Ku}$. A few outliers with high $\mathrm{CV}$ were also observed and corresponded mostly to the samples where all sites reported rainfall. The vast majority of $C V$ of $R$ samples, for instance, were within highly and moderately uniform classes and all 13 sites reported for two outliers of extreme variability. Almost all samples of the CV of $D_{\text {mass }}$ fell into the highly uniform class, but two outliers of highly variable samples had one and two sites that did not report rainfall. The majority of the samples fell into highly to mostly uniform classes for the $\mathrm{CV}$ of $N_{W}$, while highly and moderately uniform classes dominated for the $\mathrm{CV}$ of $\mu$.

Highly and mostly uniform classes had the majority of observations for the $\mathrm{CV}$ of $\mathrm{Z} \_\mathrm{Ku}$ and $\mathrm{Z} \_\mathrm{Ka}$, but the remaining three classes had a considerable number of observations, especially for the $\mathrm{CV}$ of $\mathrm{Z} \_\mathrm{Ku}$. The high dynamic range of $Z \_K u$ and $Z \_K a$ contributes to the higher variability with the DPR footprint. The CV of $\mathrm{k} \_\mathrm{Ku}$ and $\mathrm{k} \_\mathrm{Ka}$ resembled the variability of $R$. This was true for correlation analysis as well. This is not surprising given the nearly linear relationship between specific attenuation and rain rate at these frequencies (Atlas and Ulbrich 1977; Olsen et al. 1978). The CV of DSD and rain parameters did not show significantly different distributions with respect to the choice of thresholds except $D_{\text {mass }}$, which had a number of high CV samples at light rain intensity that were eliminated in reflectivitybased thresholds. 
Acknowledgments. The authors are thankful to Robert Meneghini, Mircea Grecu, and S. Joseph Munchak for their valuable comments from a GPM algorithm developer perspective. Thanks to Jianxin Wang for his help on the IDL plotting routine. Many thanks to Patrick Gatlin and Matthew Wingo for maintaining and collecting 2DVD data during MC3E. Acknowledgments extend to V.N. Bringi and Merhala Thurai for their efforts in calibrating 2DVD at the beginning of the field campaign. We appreciate DOE ARM for hosting the field campaign in their Southern Great Plains facility and providing two 2DVD databases. We acknowledge funding support from the GPM Ground Validation program provided by Matthew Schwaller. This research was funded through NASA Precipitation Measurement Mission Grant NNX16AE88G provided by Ramesh Kakar.

\section{REFERENCES}

Atlas, D., and C. W. Ulbrich, 1977: Path- and area-integrated rainfall measurement by microwave attenuation in the 1-3 cm band. J. Appl. Meteor., 16, 1322-1331, doi:10.1175/ 1520-0450(1977)016<1322:PAAIRM > 2.0.CO;2.

Beard, K. V., 1976: Terminal velocity and shape of cloud and precipitation drops aloft. J. Atmos. Sci., 33, 851-864, doi:10.1175/1520-0469(1976)033<0851:TVASOC >2.0.CO;2.

Bringi, V. N., L. Tolstoy, M. Thurai, and W. A. Petersen, 2015: Estimation of spatial correlation of drop size distribution parameters and rain rate using NASA's S-band polarimetric radar and 2D video disdrometer network: Two case studies from MC3E. J. Hydrometeor., 16, 1207-1221, doi:10.1175/ JHM-D-14-0204.1.

Ciach, G. J., and W. F. Krajewski, 2006: Analysis and modeling of spatial correlation structure of small-scale rainfall in Central Oklahoma. Adv. Water Resour., 29, 1450-1463, doi:10.1016/ j.advwatres.2005.11.003.

D'Adderio, L. P., F. Porcu, and A. Tokay, 2015: Identification and analysis of collisional breakup in natural rain. J. Atmos. Sci., 72, 3404-3416, doi:10.1175/JAS-D-14-0304.1.

Dirks, K. N., J. E. Hay, C. D. Stow, and D. Harris, 1998: Highresolution studies of rainfall on Norfolk Island. Part II: Interpolation of rainfall data. J. Hydrol., 208, 187-193, doi:10.1016/S0022-1694(98)00155-3.

Frasson, R. P. M., L. K. Cunha, and W. F. Krajewski, 2011: Assessment of the Thies optical disdrometer performance. Atmos. Res., 101, 237-255, doi:10.1016/ j.atmosres.2011.02.014.

Gatlin, P., M. Thurai, V. N. Bringi, W. Petersen, D. Wolff, A. Tokay, L. Carey, and M. Wingo, 2015: Searching for large raindrops: A global summary of two-dimensional video disdrometer observations. J. Appl. Meteor. Climatol., 54, 1069-1089, doi:10.1175/JAMC-D-14-0089.1.

Gebremichael, M., and W. F. Krajewski, 2004: Characterization of the temporal sampling error in space-time-averaged rainfall estimates from satellite. J. Geophys. Res., 109, D11110, doi:10.1029/2004JD004509.

Grecu, M., W. S. Olson, S. J. Munchak, S. Ringerud, L. Liao, Z. Haddad, B. Kelley, and S. McLaughlin, 2016: The GPM combined algorithm. J. Atmos. Oceanic Technol., 33, 2225-2245, doi:10.1175/JTECH-D-16-0019.1.
Haberlandt, U., 2007: Geostatistical interpolation of hourly precipitation from rain gauges and radar for a large-scale extreme rainfall event. J. Hydrol., 332, 144-157, doi:10.1016/ j.jhydrol.2006.06.028.

Habib, E., and W. Krajewski, 2002: Uncertainty analysis of the TRMM ground-validation radar-rainfall products: Application to the TEFLUN-B field campaign. J. Appl. Meteor., 41, 558-572, doi:10.1175/1520-0450(2002)041<0558:UAOTTG > 2.0.CO;2.

_ B. B. F. Larson, and J. Graschel, 2009: Validation of NExRAD multisensory precipitation estimates using an experimental dense rain gauge network in south Louisiana. J. Hydrology, 373, 463-478, doi:10.1016/j.jhydrol.2009.05.010.

Iguchi, T., T. Kozu, R. Meneghini, J. Awaka, and K. Okamoto, 2000: Rain profiling algorithm for the TRMM precipitation radar. J. Appl. Meteor., 39, 2038-2052, doi:10.1175/ 1520-0450(2001)040<2038:RPAFTT>2.0.CO;2.

- - - J. Kwiatkowski, R. Meneghini, J. Awaka, and K. Okamoto, 2009: Uncertainties in the rain profiling algorithm for the TRMM precipitation radar. J. Meteor. Soc. Japan, 87A, 1-30, doi:10.2151/jmsj.87A.1.

Jaffrain, J., and A. Berne, 2012: Quantification of the small-scale spatial structure of the raindrop size distribution from network of disdrometers. J. Applied Meteor. Climatol., 51, 941-953, doi:10.1175/JAMC-D-11-0136.1.

— A. Studzinski, and A. Berne, 2011: A network of disdrometers to quantify the small-scale variability of the raindrop size distribution. Water Resour. Res., 47, W00H06, doi:10.1029/2010WR009872.

Jameson, A. R., and M. L. Larsen, 2016: Estimates of the statistical two-dimensional spatial structure in rain over a small network of disdrometers. Meteor. Atmos. Phys., 128, 401-413, doi:10.1007/s00703-016-0438-0.

,-- , and A. B. Kostinski, 2015: On the variability of drop size distributions over areas. J. Atmos. Sci., 72, 1386-1397, doi:10.1175/JAS-D-14-0258.1.

,-- , and,- 2016 : An example of persistent microstructure in a long rain event. J. Hydrometeor., 17, 1661-1673, doi:10.1175/JHM-D-15-0180.1.

Jensen, M. P., and Coauthors, 2016: The Midlatitude Continental Convective Clouds Experiment (MC3E). Bull. Amer. Meteor. Soc., 97, 1667-1686, doi:10.1175/ BAMS-D-14-00228.1.

Kirstetter, P. E., Y. Hong, J. J. Gourley, M. Schwaller, W. Petersen, and Q. Cao, 2015: Impact of sub-pixel rainfall variability on spaceborne precipitation estimation: Evaluating the TRMM 2A25 product. Quart. J. Roy. Meteor. Soc., 141, 953-966, doi:10.1002/qj.2416.

Larsen, M. L., and J. B. Teves, 2015: Identifying individual rain events with a dense disdrometer network. Adv. Meteor., 2015, 582782, doi:10.1155/2015/582782.

Lee, C. K., G. W. Lee, I. Zawadzki, and K. E. Kim, 2009: A preliminary analysis of spatial variability of raindrop size distributions during stratiform rain events. J. Appl. Meteor. Climatol., 48, 270-283, doi:10.1175/2008JAMC1877.1.

Löffler-Mang, M., and J. Joss, 2000: An optical disdrometer for measuring size and velocity of hydrometeors. J. Atmos. Oceanic Technol., 17, 130-139, doi:10.1175/1520-0426(2000)017<0130: AODFMS $>2.0 . \mathrm{CO} ; 2$.

Meneghini, R., and L. Liao, 2013: Modified Hitschfeld-Bordan equations for attenuation corrected radar rain reflectivity: Application to non-uniform beam filling at off-nadir incidence. J. Atmos. Oceanic Technol., 30, 1149-1160, doi:10.1175/JTECH-D-12-00192.1. 
H. Kim, L. Liao, J. Jones, and J. Kwiatkowski, 2015: An initial assessment of the surface reference technique applied to data from dual-frequency precipitation radar (DPR) on the GPM satellite. J. Atmos. Oceanic Technol., 32, 2281-2295, doi:10.1175/JTECH-D-15-0044.1.

Moreau, E., J. Testud, and E. Le Bouar, 2009: Rainfall spatial variability observed by X-band weather radar and its implication for the accuracy of rainfall estimates. Adv. Water Resour., 32, 1011-1019, doi:10.1016/j.advwatres.2008.11.007.

Olsen, R. L., D. V. Rogers, and D. B. Hodge, 1978: The $\mathrm{aR}^{\mathrm{b}}$ relation in the calculation of rain attenuation. IEEE Trans. Antennas Propag., 26, 318-329, doi:10.1109/TAP.1978.1141845.

Porcù, F., L. Milani, and M. Petracca, 2014: On the uncertainties in validating satellite instantaneous rainfall estimates with raingauge network. Atmos. Res., 144, 73-81, doi:10.1016/ j.atmosres.2013.12.007.

Raupach, T. H., and A. Berne, 2016a: Spatial interpolation of experimental raindrop size distribution spectra. Quart. J. Roy. Meteor. Soc., 42, 125-137, doi:10.1002/qj.2801.

_ and 2016b: Small-scale variability of the raindrop size distribution and its effect on areal rainfall retrieval. J. Hydrometeor., 17, 2077-2104, doi:10.1175/JHM-D-15-0214.1.

Schönhuber, M., G. Lammer, and W. L. Randeu, 2007: One decade of imaging precipitation measurement by $2 \mathrm{D}$ video disdrometer Adv. Geosci., 10, 85-90, doi:10.5194/adgeo-10-85-2007.

Schröer, J.-B., 2011: Spatial and temporal variability of raindrop size distribution. Diploma thesis, University of Bonn, $133 \mathrm{pp}$

Seto, S., T. Iguchi, and T. Oki, 2013: The basic performance of a precipitation retrieval algorithm for the global precipitation measurement mission's single/dual-frequency radar measurements. IEEE Trans. Geosci. Remote Sens., 51, 5239-5251, doi:10.1109/TGRS.2012.2231686.

Short, D. A., K. Nakagawa, and T. Iguchi, 2012: Empirical test of theoretically based correction for path integrated attenuation in simulated spaceborne precipitation radar observations. IEEE J. Sel. Top. Appl. Earth Obs. Remote Sens., 5, 930-935, doi:10.1109/JSTARS.2012.2194695.

_ , R. Meneghini, A. E. Emory, and M. R. Schwaller, 2015: Reduction of nonuniform beamfilling effects by multiple constraints: A simulation study. J. Atmos. Oceanic Technol., 32, 2114-2124, doi:10.1175/JTECH-D-15-0021.1.

Takahashi, N., H. Hanado, and T. Iguchi, 2006: Estimation of path-integrated attenuation and its nonuniformity from TRMM/PR range profile data. IEEE Trans. Geosci. Remote Sens., 44, 3276-3283, doi:10.1109/ TGRS.2006.876295.

Tapiador, F. J., R. Checa, and M. de Castro, 2010: An experiment to measure the spatial variability of raindrop size distribution using sixteen laser disdrometers. Geophys. Res. Lett., 37, L16803, doi:10.1029/2010GL044120.

, and Coauthors, 2017: On the optimal measuring area for pointwise rainfall estimation: A dedicated experiment with 14 laser disdrometers. J. Hydrometeor., 18, 753-760, doi:10.1175/ JHM-D-16-0127.1.

Thurai, M., V. N. Bringi, L. D. Carey, P. Gatlin, E. Schultz, and W. A. Petersen, 2012: Estimating the accuracy of polarimetric radar-based retrievals of drop-size distribution parameters and rain rate: An application of error variance separation using radar-derived spatial correlations. J. Hydrometeor., 13, 1066-1079, doi:10.1175/ JHM-D-11-070.1.

Tokay, A., and D. Short, 1996: Evidence from tropical raindrop spectra of the origin of rain from stratiform and convective clouds. J. Appl. Meteor., 35, 355-371, doi:10.1175/ 1520-0450(1996)035<0355:EFTRSO > 2.0.CO;2.

—, and P. G. Bashor, 2010: An experimental study of small-scale variability of raindrop size distribution. J. Appl. Meteor. Climatol., 49, 2348-2365, doi:10.1175/2010JAMC2269.1.

— , and K. Öztürk, 2012: An experimental study of the smallscale variability of rainfall. J. Hydrometeor., 13, 351-365, doi:10.1175/JHM-D-11-014.1.

— W. A. Petersen, P. Gatlin, and M. Wingo, 2013: Comparison of raindrop size distribution measurements by collocated disdrometers. J. Atmos. Oceanic Technol., 30, 1672-1690, doi:10.1175/JTECH-D-12-00163.1.

_ R. J. Roche, and P. G. Bashor, 2014: An experimental study of spatial variability of rainfall. J. Hydrometeor., 15, 801-812, doi:10.1175/JHM-D-13-031.1.

— L. P. D'Adderio, D. B. Wolff, and W. A. Petersen, 2016: A field study of pixel-scale variability of raindrop size distribution in the mid-Atlantic region. J. Hydrometeor., 17, 1855-1868, doi:10.1175/JHM-D-15-0159.1.

Ulbrich, C. W., and D. Atlas, 1998: Rainfall microphysics and radar properties: Analysis methods for drop size spectra. J. Appl. Meteor., 37, 912-923, doi:10.1175/1520-0450(1998)037<0912: RMARPA $>2.0 . \mathrm{CO} ; 2$. 